\title{
Effects of straw mulching on soil evaporation during the soil thawing period in a cold region in northeastern China
}

\author{
Qiang Fu*, Peiru Yan, Tianxiao Li, Song Cui and Li Peng \\ College of Water Conservancy \&3 Civil Engineering, Northeast Agricultural University, Harbin 150 038, China. \\ ${ }^{*}$ Corresponding author. e-mail: fuqiang0629@126.com
}

MS received 7 March 2017; revised 23 August 2017; accepted 24 August 2017; published online 27 March 2018

To study the effect of straw mulching on soil water evaporation, it is necessary to measure soil water evaporation under different conditions of straw mulching during the soil thawing period. A field experiment was conducted in winter, and soil evaporation was measured using a microlysimeter on bare land (LD) and 4500 (GF4500), 9000 (GF9000) and $13500 \mathrm{~kg} / \mathrm{hm}^{2}$ (GF13500) straw mulch. The influence of different quantities of straw mulch on soil water evaporation during the thawing period was analyzed using the Mallat algorithm, statistical analysis and information cost function. The results showed that straw mulching could delay the thawing of the surface soil by $3-6 \mathrm{~d}$, decrease the speed at which the surface soil thaws by $0.40-0.80 \mathrm{~cm} / \mathrm{d}$, delay the peak soil liquid water content, increase the soil liquid water content, reduce the cumulative evaporation by $2.70-7.40 \mathrm{~mm}$ in the thawing period, increase the range of soil evaporation by $0.04-0.10 \mathrm{~mm}$ in the early stage of the thawing period, and reduce the range of soil evaporation by $0.25-0.90 \mathrm{~mm}$ in the late stage of the thawing period. Straw mulching could reduce the range of and variation in soil evaporation and can reduce the effect of random factors on soil evaporation. When the amount of straw mulch exceeded $9000 \mathrm{~kg} / \mathrm{hm}^{2}$, the effect of increasing the amount of straw mulch on daily soil water evaporation was small.

Keywords. Straw mulching; soil water evaporation; soil thawing period; freezing depth; soil liquid water content.

\section{Introduction}

The Songnen Plain, located in northeastern China, has $594 \times 10^{4}$ ha of cultivated land area and a grain yield of $395 \times 10^{8} \mathrm{~kg}$. It is one of the most important food production bases in China (Yan et al. 2015). Recently, owing to the impacts of climate change and increasing human activities, more than $50 \%$ of the Songnen Plain has experienced severe or extremely severe drought, and $28 \%$ has been subjected to moderate drought (Kang and Zhang 2016). Drought has become an important factor restricting the development of agricultural production in the Songnen Plain. To mitigate drought, straw mulch is often used in production. Straw mulch, which is applied directly to the surface of farmland, provides a protective layer and has the following functions: reduces soil water evaporation and regulates soil temperature $(\mathrm{Li}$ et al. 2013a), reduces topsoil salinity (Zhao et al. 2014), reduces water and soil loss (Vega et al. 2014) and increases soil fertility (Fan et al. 2014). Among these functions, the reduction in soil water evaporation plays a vital role in resisting drought. 
Numerous studies have been conducted to determine the effect of straw mulching on soil water evaporation. Bond and Willis (1970) reported that the evaporation rate decreased with increasing straw residue rates in the laboratory. $\mathrm{Li}$ et al. (2008) found that straw mulching could reduce the latent heat flux and reduced soil water evaporation in all growing seasons of winter wheat regardless of irrigation. Balwinder-Singh et al. (2011) concluded that straw mulch lowered the total evaporation over the crop growth season by 35 and $40 \mathrm{~mm}$ in relatively high- and low-rainfall years, respectively. Fuchs and Hadas (2011) found that the resistance of evaporation is related to the thickness, mulch area index and bulk density of the straw. Cao et al. (2012) demonstrated that the effect of straw mulching on evaporation was better than that of straw mixing and straw inter-layering. Li et al. (2013b) reported that straw mulching reduced soil water evaporation and increased soil water in the $0-200 \mathrm{~cm}$ soil profile in a field experiment. Zribi et al. (2015) concluded that straw mulching was ineffective in controlling soil water evaporation under low-frequency irrigation systems, but was effective for soil water evaporation control under high-frequency irrigation systems. Vial et al. (2015) found that adding straw mulch reduced the estimated soil water evaporation by $114-163 \mathrm{~mm}$ in Vientiane Province, Lao PDR. Zhang et al. (2016) calibrated CoupModel with field measurements for the Loess Plateau of China, which has a continental monsoon climate; the simulations indicated that straw mulching increased soil water storage by $38-71 \mathrm{~mm}$ during three fallow periods and decreased soil water evaporation by $22-72 \mathrm{~mm}$ compared with conventional practices. However, the above research was aimed at studying the non-freezing-thawing period, and research on the freezing-thawing period has been relatively limited. The soil contains a larger amount of ice during the freezing-thawing period than the non-freezing-thawing period, which changes the movement of soil moisture and the soil water evaporation process. The Songnen Plain, which is located at a high latitude, experiences more than 170 days of freezing-thawing each year (Fu et al. 2015a). During the freezing-thawing period, soil water evaporation occurs mainly during the thawing phase (Chen et al. 2013). Therefore, the main objective of this study was to determine the effects of straw mulching on soil water evaporation on the Songnen Plain during the thawing period.

\section{Materials and methods}

\subsection{Study area}

Experiments were carried out in the water conservation irrigation experimental field of Northeast Agricultural University in Harbin, Heilongjiang Province, from March 10 to April 14, 2016. The experimental field was located on the eastern Songnen Plain $\left(126^{\circ} 45^{\prime} \mathrm{E}, 45^{\circ} 43^{\prime} \mathrm{N}\right)$ at an average altitude of $138 \mathrm{~m}$. The experimental field site was surrounded by flat and wide-open farmland and was situated in a region that belongs to the typical black soil area of the Songnen Plain; the soil texture was uniform throughout the experimental field site (table 1). The climate type of the experimental field is temperate continental climate, which is the most typical climate type on the Songnen Plain. The winters are cold, dry and long, and the summers are hot, rainy and short. The annual average precipitation is $529 \mathrm{~mm}$, most of which is received from July to September. The annual average temperature is $3.6^{\circ} \mathrm{C}$, the average temperature in winter is $-14.2^{\circ} \mathrm{C}$, and the average temperature in summer is $19.8^{\circ} \mathrm{C}$. The average snow cover period is 110 days, and the frost-free period is approximately 140 days. The maximum freezing depth is $180 \mathrm{~cm}$, and the groundwater depth is $6.8 \mathrm{~m}$. The soil layer between 0 and $30 \mathrm{~cm}$ is black loam, below which black clay occurs.

\subsection{Measurements}

We set up a total of eight test plots; the size of each plot was $10 \times 10 \mathrm{~m}$, which is larger than common test plots (Ram et al. 2013; Zhao et al. 2014); this was done to ensure the observational accuracy of the instruments and improve the accuracy of the experiments. The area surrounding each plot was embedded with plastic sheets ( $2 \mathrm{~m}$ deep) to prevent lateral drainage between plots. The plots were divided into two groups, and each group was treated with four different treatments: bare land (LD), $4500 \mathrm{~kg} / \mathrm{hm}^{2}$ of straw mulch (GF4500), $9000 \mathrm{~kg} / \mathrm{hm}^{2}$ of straw mulch (GF9000), and 13500 $\mathrm{kg} / \mathrm{hm}^{2}$ of straw mulch (GF13500). Each treatment had two replications, and three microlysimeters were used to measure soil evaporation within each plot (figure 1) to reduce experimental error. This study focused on soil evaporation during the soil thawing period. The soil thawing period lasted for 1 month (figure 2); thus, observations were collected for 1 month. After all the snow had melted, 
Table 1. Soil physical parameters of the different treatments.

\begin{tabular}{|c|c|c|c|c|c|c|c|}
\hline \multirow[b]{2}{*}{ Treatment } & \multirow{2}{*}{$\begin{array}{c}\text { Natural water } \\
\text { content }(\%)\end{array}$} & \multirow{2}{*}{$\begin{array}{c}\text { Saturated } \\
\text { water content } \\
(\%)\end{array}$} & \multirow{2}{*}{$\begin{array}{c}\text { Field } \\
\text { water-holding } \\
\text { capacity }(\%)\end{array}$} & \multirow{2}{*}{$\begin{array}{l}\text { Dry density } \\
\left(\mathrm{g} / \mathrm{cm}^{3}\right)\end{array}$} & \multicolumn{3}{|c|}{ Mechanical composition/(\%) } \\
\hline & & & & & Clay $(\%)$ & Silt (\%) & Sand $(\%)$ \\
\hline $\mathrm{LD}$ & $23.18( \pm 0.17)^{\mathrm{a}}$ & $40.82( \pm 1.05)^{\mathrm{a}}$ & $28.26( \pm 1.23)^{\mathrm{a}}$ & $1.33( \pm 0.05)^{\mathrm{a}}$ & $18.15( \pm 0.54)^{\mathrm{a}}$ & $36.92( \pm 0.59)^{\mathrm{a}}$ & $44.93( \pm 0.66)^{\mathrm{a}}$ \\
\hline GF4500 & $23.07( \pm 0.21)^{\mathrm{a}}$ & $42.47( \pm 1.55)^{\mathrm{a}}$ & $27.40( \pm 1.10)^{\mathrm{a}}$ & $1.37( \pm 0.07)^{\mathrm{a}}$ & $18.26( \pm 0.82)^{\mathrm{a}}$ & $36.77( \pm 0.55)^{\mathrm{a}}$ & $44.97( \pm 0.47)^{\mathrm{a}}$ \\
\hline GF9000 & $23.21( \pm 0.19)^{\mathrm{a}}$ & $39.89( \pm 2.07)^{\mathrm{a}}$ & $26.86( \pm 1.61)^{\mathrm{a}}$ & $1.30( \pm 0.07)^{\mathrm{a}}$ & $18.61( \pm 0.58)^{\mathrm{a}}$ & $37.01( \pm 0.56)^{\mathrm{a}}$ & $44.38( \pm 0.60)^{\mathrm{a}}$ \\
\hline GF13500 & $23.32( \pm 0.31)^{\mathrm{a}}$ & $42.84( \pm 1.57)^{\mathrm{a}}$ & $29.07( \pm 1.61)^{\mathrm{a}}$ & $1.35( \pm 0.08)^{\mathrm{a}}$ & $18.34( \pm 0.55)^{\mathrm{a}}$ & $36.90( \pm 0.56)^{\mathrm{a}}$ & $44.76( \pm 0.58)^{\mathrm{a}}$ \\
\hline
\end{tabular}

Values within a column followed by the same letter are not significantly different (LSD, $P<0.05)$.

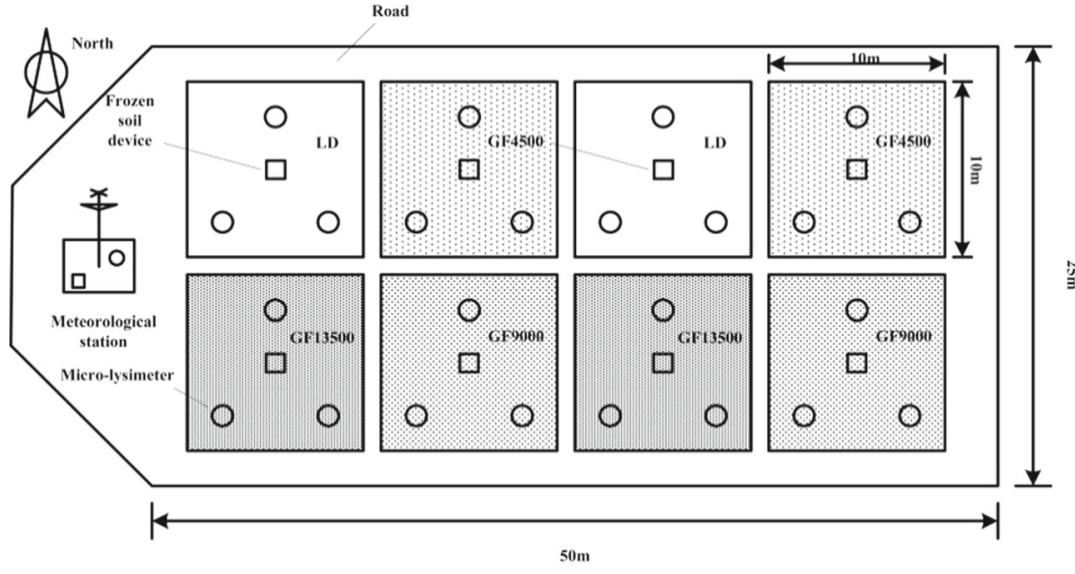

(a) Layout of the experimental area

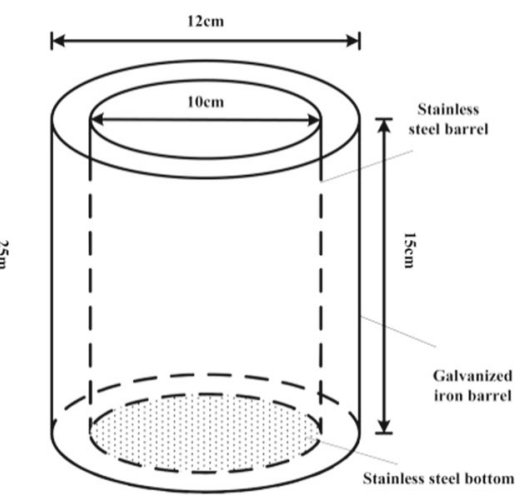

(b) Microlysimeter

Figure 1. (a) Layout of experimental area. (b) Microlysimeter. Experimental set-up for the various experimental treatments. LD denotes bare land; GF4500, GF9000 and GF13500 denote an initial coverage of 4500, 9000 and $13500 \mathrm{~kg} / \mathrm{hm}{ }^{2} \mathrm{straw}$, respectively.

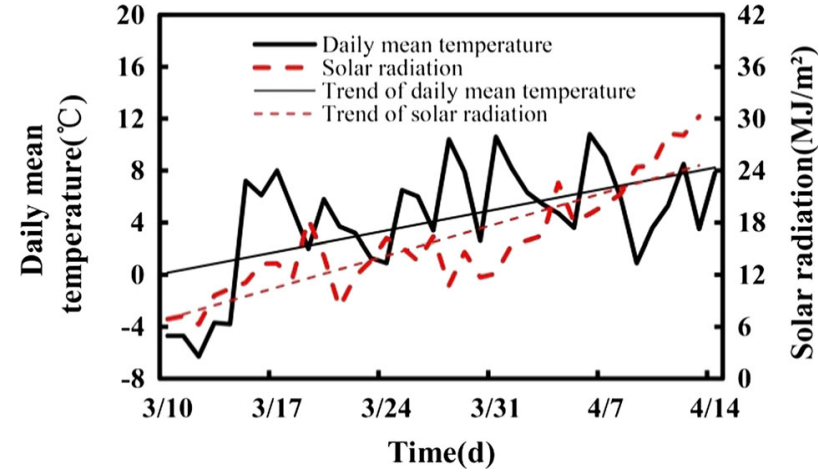

Figure 2. Average daily temperature, total daily radiation and their variation during the thawing period.

the plots were covered with straw. The straw was whole corn straw that was harvested in 2015; leaves were retained on the straw, and the straw was placed in a vertical position. The straw was approximately $2 \mathrm{~m}$ in length, and the straw was evenly laid.

Microlysimeters were used to measure soil water evaporation. The microlysimeters were composed of two parts: an inner and an outer barrel. The inner barrel was constructed of stainless steel and had a diameter of $10 \mathrm{~cm}$ and a height of $15 \mathrm{~cm}$. The outer barrel was constructed of galvanized iron and had a diameter of $12 \mathrm{~cm}$ and a height of $15 \mathrm{~cm}$. The outer barrel had a fixed position and protected the structure from the surrounding soil. The inner barrel was pressed into the soil, and the undisturbed soil was removed. The soil bottom was flattened and covered with a lid, and the inner barrel was placed into the outer barrel. Three microlysimeters were placed in each plot. To minimize the difference between the soil core and the surrounding soil, an undisturbed soil core was renewed every three days under normal conditions or immediately after rainfall. The microlysimeters with undisturbed soil were weighed every day at 8:00 a.m. using an electronic scale (sensitivity of $0.01 \mathrm{~g}$ ). The difference between two results represented soil water evaporation. A small amount of rain occurred on April 1, 6, 12 and 13; consequently, soil water evaporation could not be measured on those days. The change in the freezing depth 
was measured daily using a frozen soil device (LQX-DT, Jinzhou Licheng Automation Equipment Co., Ltd., Jinzhou, China). The frozen soil device was placed in the center of each plot (as shown in figure 1). There was a rubber tube filled with water in the frozen soil device. The zero tick mark was flush with the ground. The depth of the ice in the rubber tube was measured at 9 a.m. and represented the soil freezing depth. The soil liquid water content was measured by TDR. Meteorological conditions during the test period were measured by a small automatic weather station located in the test area; these data were recorded once in every hour.

\subsection{Research methods}

\subsubsection{Mallat algorithm for the identification of the daily soil water evaporation trend}

To accurately analyze the daily evaporation trend of soil under different straw mulching conditions, the Mallat algorithm was used to decompose and reconstruct the time series of soil water evaporation. The Mallat algorithm can identify high- and low-frequency sequences at different scales, and the low-frequency sequence represents the variation trend of the scale. The Mallat decomposition and reconstruction formulas are as follows (Xue et al. 2002):

$$
\begin{gathered}
c_{j, k}=\sum_{m} h_{0}(m-2 k) c_{j-1, k} \\
d_{j, k}=\sum_{m} h_{1}(m-2 k) d_{j-1, k} \\
c_{j-1, m}=\sum_{k} c_{j, k} h_{0}(m-2 k) \\
\quad+\sum_{k} d_{j, k} h_{1}(m-2 k)
\end{gathered}
$$

where $j$ is the decomposition scale; $m$ and $k$ are translation parameters; $c_{j, k}$ is the low-frequency coefficient; $d_{j, k}$ is the high-frequency coefficient; and $h_{0}(n)$ and $h_{1}(n)$ are low- and high-pass filters, respectively.

The steps involved in using the Mallat algorithm to determine daily soil water evaporation under different straw mulching conditions are as follows:

- The Mallat algorithm was used to decompose the time series of soil water evaporation under different straw mulching conditions, and the low- and high-frequency coefficients were obtained;
- The coefficients of different scales were reconstructed, and the low-frequency sequences of soil water evaporation under different straw mulching conditions were obtained;

- The low-frequency sequences were analyzed, and the soil water evaporation trend under different straw mulching conditions was obtained.

\subsubsection{Method to identify daily soil water evaporation differences}

A statistical analysis was performed to reveal the differences in soil water evaporation under different straw mulching conditions. Specifically, the range $R$, standard deviation $\sigma$, mean $\bar{X}$ and coefficient of variation $C_{v}$ of daily evaporation were calculated. The range reflects the variation in daily soil water evaporation between different treatments; the standard deviation reflects the degree of dispersion of daily soil water evaporation between different treatments; the mean value represents the average daily soil water evaporation between different treatments; and the coefficient of variation can eliminate the influence of scale and dimension and reflects the difference degree of daily soil water evaporation in different treatments. The specific formulas used are as follows (Chen et al. 2013):

$$
\begin{aligned}
R & =X_{\max }-X_{\min }, \\
\bar{X} & =\frac{1}{n} \sum_{i=1}^{n} X_{i}, \\
\sigma & =\sqrt{\frac{1}{n-1} \sum_{i=1}^{n}\left(X_{i}-\bar{X}\right)^{2},} \\
C_{v} & =\frac{\sigma}{\bar{X}}
\end{aligned}
$$

$X_{\min }$ and $X_{\max }$ are the minimum and maximum value of daily soil water evaporation in a particular treatment, respectively and $n$ is the number of treatments.

To further determine the effect of straw mulching on the differences in daily soil water evaporation during the thawing period, boxplots of daily soil water evaporation were plotted. Boxplots use five points (minimum, 1st quartile, median, 3rd quartile and maximum) to describe a set of data. These plots are graphical displays of data (Niu et al. 2015) and can directly reflect the symmetry and distribution of data, which can supplement the range, standard deviation and coefficient of variation. 


\subsubsection{Information cost function (ICF) used to identify the complexity of daily soil water evaporation}

To study the complexity of daily soil water evaporation under different straw mulching conditions, the information cost function (ICF) was used to determine the energy distribution information. More complex time series of soil daily water evaporation have greater ICF values; on the contrary, if the sequence is more orderly, the ICF value is smaller. The calculation steps are as follows (Figliola and Serrano 1997; Fu et al. 2016):

- The wavelet transform coefficients of the daily soil water evaporation sequence at different scales were calculated using the wavelet transform function:

$$
S_{j, k}=a^{-j / 2} \int_{-\infty}^{+\infty} f(t) \bar{\psi}\left(a^{-j / 2} t-k b\right) \cdot d t
$$

where $S_{j, k}$ is the wavelet transform coefficient; $\psi(t)$ is the mother wavelet function; $a$ is a time scale parameter; $t$ is a time transform factor; $j$ is the decomposition scale; and $f(t)$ is the daily soil water evaporation sequence.

- The wavelet transform coefficients were used to calculate the energy $E_{j}$ and total energy $E$ of the time series at different scales as follows:

$$
\begin{aligned}
E_{j} & =\sum_{k=1}^{n} d_{j, k}^{2}, \quad j=1,2, \ldots, M \\
E & =\sum_{j=1}^{M} E_{j}
\end{aligned}
$$

where $k$ is the number of discrete wavelet transforms at the $j$ scale, and $M$ is the maximum decomposition scale.

- The energy distribution $p_{j}$ of the time series was calculated at different scales using the following formula

$$
P_{j}=\frac{E_{j}}{E} .
$$

- The energy probability distribution of the Shannon entropy was defined as the ICF

$$
I C F=-\sum_{j=1}^{M} p_{j} \lg p_{j}
$$

\subsection{Data analysis}

Mean comparisons were performed using Fisher's LSD (the least significant difference) test at $P<$ 0.05. The analysis was conducted using the SPSS program.

\section{Results and discussion}

\subsection{Meteorological conditions and soil texture during the experimental period}

During the experimental period, the direct rays of the sun moved from the Southern to the Northern Hemisphere, the solar elevation angle increased continuously, and the duration and intensity of solar radiation increased continuously. Therefore, the daily average temperature and solar radiation in the experimental period showed an increasing trend (figure 2). Meanwhile, due to the presence of a polar continental air mass, the total rainfall was less than $10 \mathrm{~mm}$, the air was dry, and there was frequent and high wind throughout the experimental period. Before the experiment was initiated, the undisturbed soil was collected by ring knife at different points in the experimental field, and the initial water content, saturated water content and dry bulk density of the soil were measured using the drying method. The field water-holding capacity was determined using Wilcock's method. Three samples were measured in each plot. The results, presented in table 1 , show no significant differences in the soil physical parameters under the different treatments.

\subsection{Effect of straw mulching on the soil thawing process}

Curves showing the thawing process of soil under different straw mulching conditions were constructed based on the experimental results obtained from the frozen soil device (figure 3).

Figure 3 indicates that in the early stage of the experiment, the maximum soil freezing depth was $92 \mathrm{~cm}$. Subsequently, the soil began to thaw, both at the surface and underground, and the underground frozen layer began to thaw on March 10 due to the supply of underground thermal energy. When the air temperature rises to $0^{\circ} \mathrm{C}$, the atmospheric temperature is higher than the surface temperature. At this point, heat from the atmosphere is transferred to the soil surface, and the frozen soil surface layer begins to thaw. With a 
rapid increase in atmospheric temperature and solar radiation, the amount of heat transferred from the atmosphere to the soil surface is far greater than the supply of underground thermal energy, resulting in a faster thawing rate of the surface soil compared with the underground frozen layer.

In addition, figure 3 indicates that soil in LD and GF4500 began to thaw almost at the same time, but the surface thawing rate of LD was approximately $3.00 \mathrm{~cm} / \mathrm{d}$, which was faster than that for GF9000 (approximately $2.30 \mathrm{~cm} / \mathrm{d}$ ). However, thawing of the surface soil in GF9000 and GF13500 occurred later than in LD (1 d and 2 $\mathrm{d}$, respectively), indicating a slower rate of soil thawing compared with bare land. The soil in LD had thawed completely by April 8, whereas complete soil thaw in GF4500, GF9000 and GF13500 occurred $3 \mathrm{~d}, 5 \mathrm{~d}$ and $6 \mathrm{~d}$ later, respectively. This showed that straw mulching can slow down the rate of soil thawing during the thawing period.

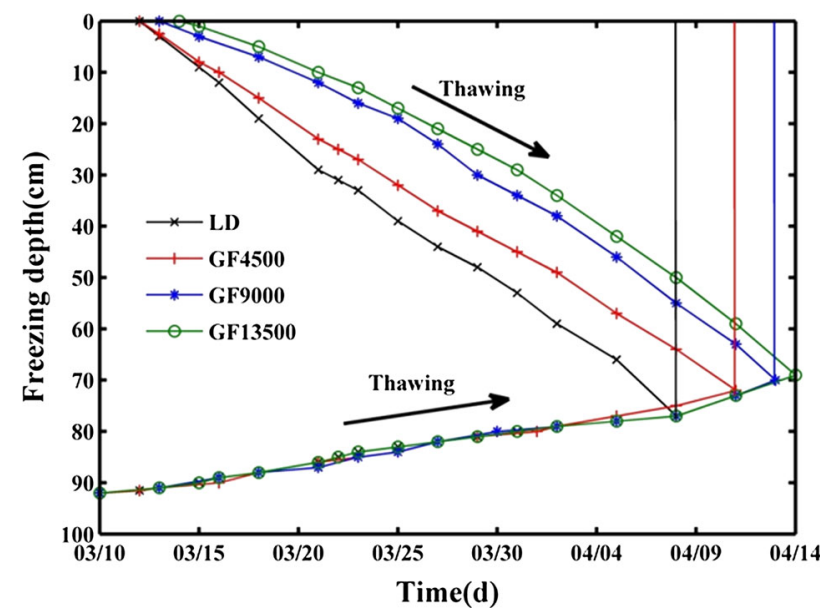

Figure 3. Soil thawing process in the different treatments.

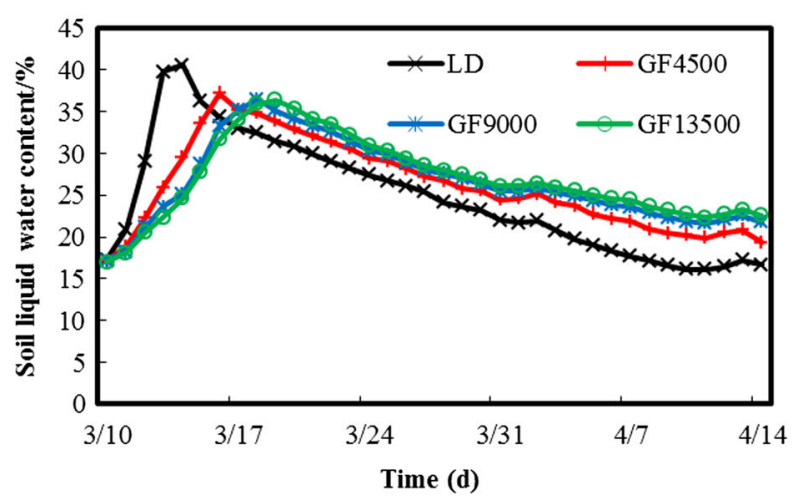

(a)
Liang et al. (2015) reported similar results for the Hetao Irrigation District of Inner Mongolia. In addition, Zhang et al. (2010) found that snow cover can also delay the rate of soil thawing. This is mainly due to increased atmospheric temperature and solar radiation during the thawing period, where the heating value of the atmosphere is higher than that of the soil. At this stage, heat is mainly transferred from the atmosphere to the soil (Fu et al. 2014). Due to its high reflectivity and insulating properties, straw can reduce net radiation and does not allow the transfer of atmospheric heat to the soil (Horton et al. 1996). Furthermore, the soil moisture content under straw mulch was higher than that of LD. Because of the large heat capacity of water, the soil heating rate under straw mulch was slower than that of LD. The soil temperature gradient under straw mulch was smaller than that of LD, and the soil heat transfer under straw mulch was lesser than that of LD. The thawing rate of the underground frozen layer under the different straw mulching conditions was similar $(0.40 \mathrm{~cm} / \mathrm{d})$, which indicates that straw mulching only affected the thawing rate of the surface soil and did not affect the thawing rate of the underground frozen layer.

\subsection{Effect of straw mulch on the soil liquid water content during the thawing period}

Changes in the observed soil liquid water content under different straw mulching conditions were analyzed, indicating that the soil liquid water content of the four different treatments showed an initial increasing trend followed by a decreasing trend (figure 4). This response was due to increased atmospheric temperatures, causing the soil ice to gradually melt at first. When the topsoil melted

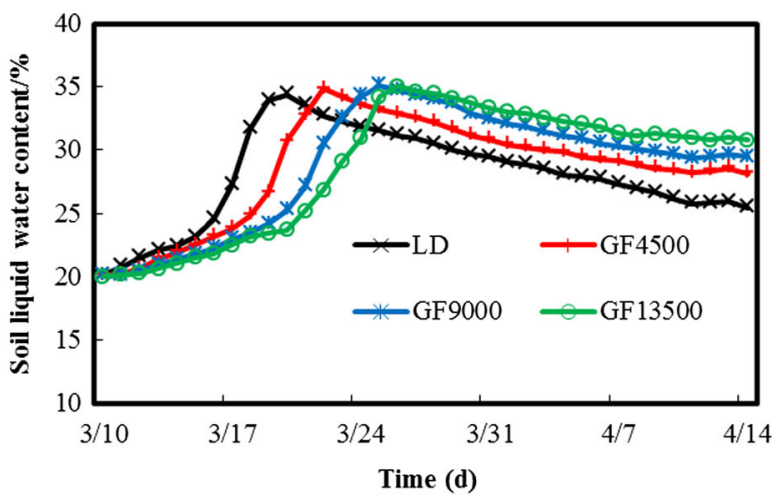

(b)

Figure 4. Soil liquid water content during the thawing period for (a) $10 \mathrm{~cm}$ and (b) $20 \mathrm{~cm}$ layers. 


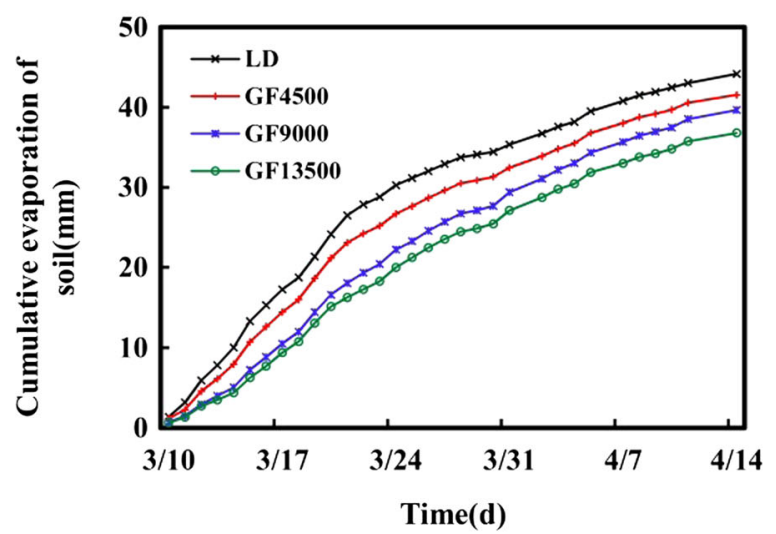

(a)

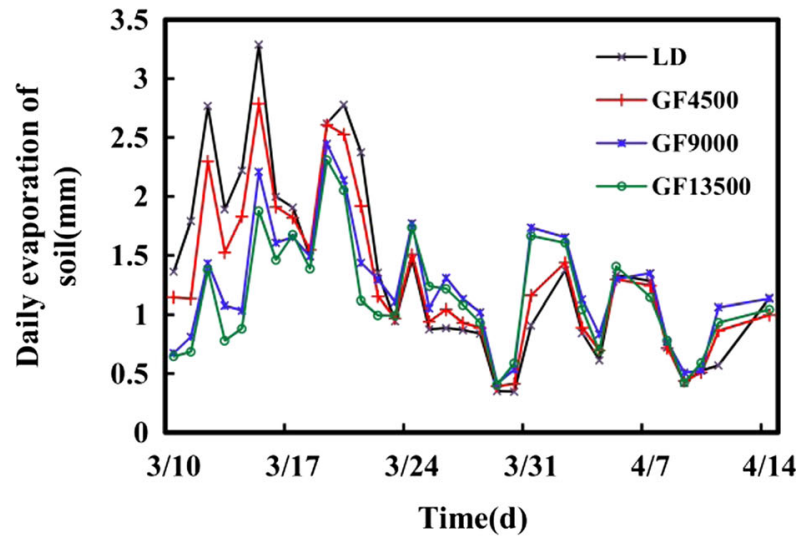

(b)

Figure 5. Comparison of evaporation under different straw mulching conditions during the thawing period. (a) Cumulative evaporation during the thawing period and (b) daily evaporation during the thawing period.

completely, the soil liquid water content decreased gradually due to soil evaporation. In addition, there were some differences between the different treatments. The soil liquid water content peak for LD was $2-5 \mathrm{~d}$ earlier than that under straw mulching conditions for a $10-\mathrm{cm}$ soil layer and $2-6 \mathrm{~d}$ earlier than that under straw mulching conditions for a $20-\mathrm{cm}$ soil layer. This result was mainly because straw mulch inhibited the thawing of frozen soil. In the late stage of soil thawing, the soil liquid water content under straw mulching was higher than that of the LD treatment. The soil liquid water content under straw mulching was $2.5-6 \%$ higher than that of the BL treatment for a 10-cm soil layer and 2.5$5.5 \%$ higher for a $20-\mathrm{cm}$ soil layer. Similar results have also been found in the non-freezing-thawing period. Ram et al. (2013) reported that the soil moisture in the no-mulch treatment was lower than that in the mulched treatments and increased with increasing mulching quantity in northwest India. Li et al. (2012) found that the average soil water content $(0-200 \mathrm{~cm})$ over 3 years was significantly increased with straw mulching compared with no mulching (by $27 \mathrm{~mm}$ at the sowing stage and $34 \mathrm{~mm}$ at the jointing stage).

Because straw mulching increased the soil moisture and provided a better hydrothermal regime, it increased the crop yield (Chakraborty et al. 2008). Huang et al. (2005) found that straw mulch increased wheat yields by $52 \%$ in 1997 and by $26 \%$ in 1998. Kar and Kumar (2007) reported that rice straw mulch application increased potato tuber production by $24-42 \%$ in eastern India.

It is well established that straw mulching can suppress soil evaporation, which can account for $30-60 \%$ of the total evapotranspiration during wheat production (Siddique et al. 1990). This suggests that straw mulching can decrease water use and increase water use efficiency. Shaheen et al. (2010) found that straw mulching improved sorghum grain and stover yields, decreased water use, and increased water use efficiency for sorghum. Similar results were also found for maize and wheat (Huang et al. 2005; Cai et al. 2016).

\subsection{Effect of straw mulch on soil water evaporation during the thawing period}

Daily and cumulative evaporation under different straw mulching conditions during the thawing period is shown in figure 4 .

The cumulative evaporation process for the four different treatments is similar, as shown in figure 4(a); evaporation accumulated rapidly in the early stage of thawing and slowed in the later stage. Figure 5(a) indicates that the cumulative evaporation of LD was $2.70,4.50$ and $7.40 \mathrm{~mm}$ greater than that in the GF4500, GF9000 and GF13500 treatments, respectively. This shows that straw mulching can reduce cumulative evaporation from the soil and that more coverage results in more profound effects. This is consistent with the effect of straw mulching on cumulative soil water evaporation during the non-freezing period (Balwinder-Singh et al. 2011). Balwinder-Singh et al. (2011) also found that straw mulching lowered the total Es over the crop growth season by 35 and $40 \mathrm{~mm}$ in relatively high- and lowrainfall years in India, respectively. Chen et al. (2007) reported that the mean daily evaporation from less mulching and more mulching was reduced by $16 \%$ and $37 \%$ compared with that 
from no mulching on the North China Plain, respectively. However, it has been reported that straw mulching only affects the soil water evaporation rate in the early stage and has little effect on cumulative soil water evaporation in the laboratory (Bond and Willis 1969, 1970). This is mainly because the soil column in the laboratory did not receive rainfall and did not have access to a water supply from deep soil. Straw mulch can provide a physical barrier between the soil and atmosphere and can prevent direct solar radiation from reaching the ground ( $\mathrm{Li}$ et al. 2008). In addition, straw mulch can also reduce the vapour pressure close to the surface, thereby reducing the driving force of soil water evaporation and preventing the transfer of soil water to the atmosphere. Greater amounts of straw mulch result in lower water loss rates. Straw mulching can reduce the soil heat flux ( $\mathrm{Li}$ et al. 2008), decrease the soil temperature, and slow the process of soil thawing. Under straw mulching conditions, considerable water is retained in the soil in a solid state, which prevents the movement of soil water from deep layers to the surface layer. The soil temperature of LD was higher than that of the straw mulch; consequently, the water in the surface soil had more energy, lower liquid surface tension and viscous force, and was more active, which facilitated the transfer of water from the soil to the atmosphere.

Prior to March 22, the highest daily soil water evaporation was measured in LD, and as the straw mulch quantity increased, soil water evaporation gradually decreased. Subsequently, the daily soil water evaporation of $\mathrm{LD}$ was lower than that measured in the straw mulch treatments (figure $5 \mathrm{~b}$ ). Cai et al. (2011) obtained similar results for the entire maize growing period. There are two main reasons for this phenomenon. On the one hand, the straw mulch delayed soil thawing by slowing the rate at which the soil thawed. During the early stage of the experiment, the liquid water content in the surface soil of LD was higher than that under the straw mulch conditions, and the soil temperature of LD was higher than that measured in the treatments with straw mulch. On the other hand, after the surface soil thawed, the liquid water content in the surface soil was high. Capillary flow to the soil surface was sufficient to meet the evaporative demand of the aboveground environment (Lemon 1956). At this point, soil water evaporation depends mainly on the atmosphere, and straw mulch can reduce the influence of solar radiation, wind speed and other weather conditions (Li et al. 2011). Therefore, daily soil water evaporation of $L D$ was higher than that measured in the straw mulch treatments before March 22. Because of the high soil water evaporation in the early stage, the moisture content in the surface soil decreased continuously in the late stage. The soil moisture content was lower than the critical soil moisture content, which is the equilibrium point between the evaporation intensity and the soil capillary water delivery capacity. The continuous state of capillary flow in the soil gradually decreased, and moisture transported through capillary flow to the soil surface reduced gradually. Capillary flow to the soil surface was not sufficient to meet the evaporative demand of the aboveground environment. Therefore soil moisture was the limiting factor for soil water evaporation (Zribi et al. 2015). In the early stage, soil water evaporation of LD was higher than that of the straw mulch treatments, resulting in a lower soil moisture in LD. Consequently, in the late stage, daily soil water evaporation in LD was lower than that in the straw mulch treatments.

\subsection{Effect of straw mulching on the trends in daily soil water evaporation during the thawing period}

Because soil water evaporation is affected by various weather conditions, soil moisture, soil temperature and other factors, soil water evaporation may be fraught with uncertainty. Time series of daily soil water evaporation cannot accurately reflect the variation trend. Therefore, daily soil water evaporation time series were decomposed and reconstructed using the Mallat algorithm; the low-frequency reconstruction sequence represents the trend of daily soil water evaporation (figure 6).

Figure 6 indicates that daily soil water evaporation of LD generally remained unchanged before March 14, after which it declined rapidly. The daily soil water evaporation of GF4500, GF9000 and GF13500 also exhibited a turning point on March 14; however, these treatments first exhibited an increase followed by a decreasing trend, and as the amount of straw mulch increased, the rate of increase in daily soil evaporation in the early stage also increased. The rate of increase for GF4500 was the highest $(0.02 \mathrm{~mm} / \mathrm{d})$. As the amount of straw mulch increased, the rate of decline in daily soil evaporation decreased in the later stage. The decline rate of $\mathrm{LD}$ was the highest $(0.03 \mathrm{~mm} / \mathrm{d})$. 


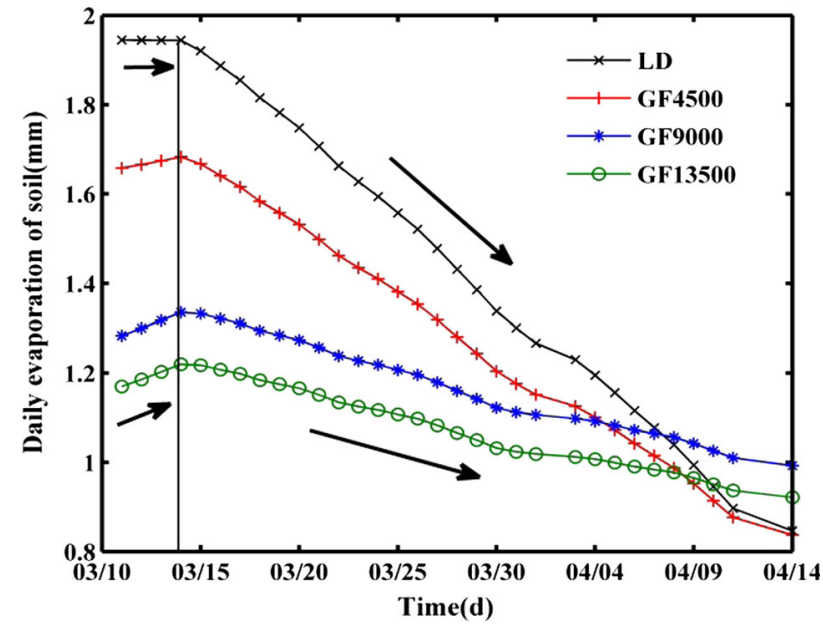

Figure 6. Daily evaporation trends of different treatments during the thawing period.

This showed that straw mulching increased the growth rate of soil water evaporation in the early stage of soil thawing and decreased the decline rate of soil water evaporation in the later stage of soil thawing. This is mainly because LD received direct solar radiation in the early stage of soil thawing. During this stage, the soil temperature in LD was high (Fu et al. 2014), the soil thawing rate was rapid, there was a sufficient soil moisture supply (Fu et al. 2015b), and the soil water was active. However, straw mulching hindered the transfer of heat and reduced the thawing of the surface soil; consequently, the temperature and liquid water content of the surface soil exhibited a slow growth process. In the late stage of soil thawing, soil water evaporation resulted in a decrease in soil moisture, and the soil moisture supply was insufficient, resulting in a downward trend in soil water evaporation. In addition, the straw mulch reduced the influence of meteorological conditions on soil water evaporation. Therefore, the decline rate of daily evaporation in the straw mulch treatments was significantly lower than that in LD.

\subsection{Effect of straw mulching on the differences in daily soil water evaporation during the thawing period}

The mean, range, standard deviation and coefficient of variation of soil water evaporation under different straw mulching conditions were calculated using formulas (4-7).

Table 2 indicates that LD had the maximum range $(2.94 \mathrm{~mm})$, and as the amount of straw mulch increased, the daily soil water evaporation
Table 2. The difference in daily evaporation between the different treatments.

\begin{tabular}{lcccc}
\hline Treatment & $\begin{array}{c}\text { Mean } \\
(\mathrm{mm})\end{array}$ & $\begin{array}{c}\text { Range } \\
(\mathrm{mm})\end{array}$ & $\begin{array}{c}\text { Standard } \\
\text { deviation }\end{array}$ & $\begin{array}{c}\text { Coefficient of } \\
\text { variation }\end{array}$ \\
\hline LD & $1.38^{\mathrm{a}}$ & 2.94 & 0.79 & 0.57 \\
GF4500 & $1.30^{\mathrm{a}}$ & 2.39 & 0.64 & 0.49 \\
GF9000 & $1.24^{\mathrm{b}}$ & 2.03 & 0.50 & 0.40 \\
GF13500 & $1.15^{\mathrm{b}}$ & 1.90 & 0.47 & 0.40 \\
\hline
\end{tabular}

$\overline{\text { Values followed by the same letter are not significantly }}$ different (LSD, $P<0.05$ ).

range decreased. This showed that straw mulching reduced the variation in soil water evaporation, and greater amounts of straw mulch resulted in smaller soil water evaporation variations. As the amount of straw mulch increased by $4500 \mathrm{~kg} / \mathrm{hm}^{2}$, the range decreased by $0.55,0.36$ and $0.04 \mathrm{~mm}$, respectively. The coefficient of variation and the standard deviation of soil water evaporation of LD were 0.57 and 0.79 , respectively, i.e., much higher than under straw mulching conditions, and greater amounts of straw mulch resulted in smaller coefficients of variation and standard deviations. GF9000 and GF13500 had the same coefficient of variation for soil water evaporation, and the difference in standard deviation between these treatments was very small, only 0.03 . This showed that straw mulching restricted the variation in daily soil water evaporation, and as the amount of straw mulch increased, the inhibitory effect was more obvious. Increases in the amount of straw mulch above $9000 \mathrm{~kg} / \mathrm{hm}^{2}$ had a very small effect on soil water evaporation. Similarly, in the non-freezing period, straw mulching also reduced the variation in soil water evaporation, and greater amounts of straw mulch resulted in more stable soil water evaporation (Sun et al. 2011, 2012). There are three main reasons for this phenomenon. First, straw mulch forms an insulation layer between the soil and atmosphere and acts as a buffer. It can effectively reduce the influence of various meteorological factors on soil water evaporation. Second, straw mulch can reduce the range in soil moisture throughout the entire thawing period, and greater amounts of straw mulch results in smaller soil moisture ranges (Xing et al. 2012; Chen et al. 2013; Fu et al. 2015a). Third, straw mulch can reduce the changes in soil temperature in different soil layers (Chen et al. 2013; Fu et al. 2014). Thus, straw mulch decreased the range and extent of daily soil water evaporation based on our observations. 


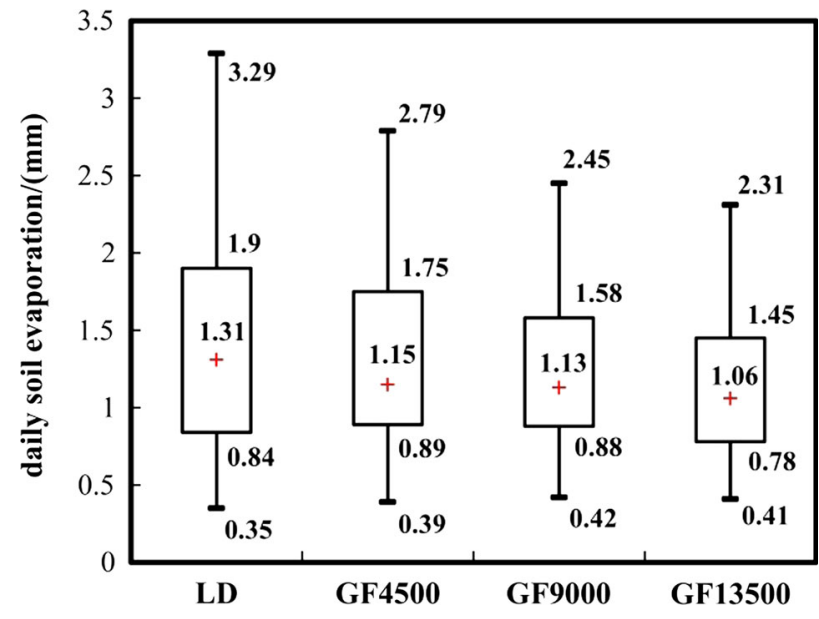

Figure 7. Boxplots of different treatments.

Table 3. ICF values of daily evaporation of different straw mulching treatments.

\begin{tabular}{lcccccc}
\hline & \multicolumn{5}{c}{ The decomposition number } & \\
\cline { 2 - 6 } Treatment & 1 & 2 & 3 & 4 & 5 & ICF \\
\hline LD & 8.86 & 21.56 & 21.04 & 21.69 & 26.85 & 0.6767 \\
GF4500 & 7.72 & 19.22 & 18.95 & 39.96 & 14.16 & 0.6398 \\
GF9000 & 7.96 & 15.26 & 17.62 & 56.85 & 2.33 & 0.5225 \\
GF13500 & 7.76 & 15.25 & 17.04 & 57.57 & 2.39 & 0.5184 \\
\hline
\end{tabular}

To further determine the effect of straw mulching on the differences in daily soil water evaporation during the thawing period, boxplots of daily soil water evaporation were plotted (figure 6). A boxplot is a graphical display of data (Niu et al. 2015) and can directly reflect the symmetry and distribution of data, which can supplement the range, standard deviation and coefficient of variation.

Figure 7 indicates that as the amount of straw mulch increased, the interquartile ranges of daily soil water evaporation decreased; these values were $1.06,0.86,0.70$ and $0.67 \mathrm{~mm}$ for LD, GF4500, GF9000 and GF13500, respectively. At the same time, the range of the upper $(1.98,1.64,1.32$ and $1.25 \mathrm{~mm}$ ) and lower halves $(0.96,0.76,0.71$ and $0.65 \mathrm{~mm}$ ) also decreased. This further showed that straw mulching reduced the range of soil water evaporation. The median also decreased with an increase in the amount of straw mulch, i.e., $1.31,1.15,1.13$ and $1.06 \mathrm{~mm}$ for LD, GF4500, GF9000 and GF13500, respectively. This indicates that straw mulching reduced soil water evaporation during the thawing period. The range in soil water evaporation in the lower part of the four treatments $(0.96,0.76,0.71$ and 0.65 $\mathrm{mm}$ ) was smaller than that of the upper part $(1.98,1.64,1.32$ and $1.25 \mathrm{~mm})$. This showed that soil water evaporation was low during the thawing period. There are two main reasons for this phenomenon. First, atmospheric temperature and solar radiation were low in the thawing period. Second, less rainfall occurred during the thawing period, and the soil moisture supply was insufficient.

\subsection{Effect of straw mulching on the complexity of daily soil water evaporation during the thawing period}

Due to the considerable randomness of meteorological conditions, soil water evaporation is greatly affected by weather (Ben Neriah et al. 2014; Davarzani et al. 2014), which also exhibits certain complex characteristics. To reveal the effect of straw mulching on the complexity of daily soil water evaporation, the daily soil water evaporation time series were analyzed using the ICF. The ICF values of the different treatments are presented in table 3 .

Table 3 indicates that LD had the highest ICF value, which was $0.0369,0.1542$ and 0.1583 higher than that of GF4500, GF9000 and GF13500, respectively. This showed that straw mulching can reduce the effect of various random factors on soil water evaporation, and as the amount of straw mulch increased, the effect of random factors on soil water evaporation was gradually reduced. A small amount of straw mulch exerted little control on the random factors in contrast to a large amount of straw mulch. When the amount of straw mulch exceeded $9000 \mathrm{~kg} / \mathrm{hm}^{2}$, the controlling effect of increasing the amount of straw mulch on the random factors was not obvious. This was mainly because the straw mulch prevented direct contact between the atmosphere and the soil and reduced the influence of meteorological factors, such as wind. A small amount of straw mulch could not cover the soil surface completely; consequently, the controlling effect on random factors was not obvious. When the amount of straw mulch increased to $9000 \mathrm{~kg} / \mathrm{hm}^{2}$, the soil surface was completely covered by straw, which resulted in adequate control of random factors.

\section{Conclusions}

By analyzing the effects of straw mulch on soil freezing depth, liquid water content and 
evaporation, it can be concluded that soil thawing occurred at both the top and the bottom of the frozen soil layer. Although the bottom of the frozen soil layer began to thaw first, the rate at which the surface soil thawed was greater. Because straw mulch blocked atmospheric heat, it delayed the thawing of topsoil, decreased the rate of soil thawing and delayed the peak soil liquid water content. During the thawing period, the straw mulch reduced the cumulative soil water evaporation by $2.90-7.40 \mathrm{~mm}$ and increased soil moisture content by $2.5-6 \%$. Straw mulch increased the rate of soil water evaporation growth by $0.01-$ $0.02 \mathrm{~mm} / \mathrm{d}$ in the early stage of the soil thawing period and reduced the rate of soil water evaporation decline by $0.01-0.03 \mathrm{~mm} / \mathrm{d}$ in the late stage of the soil thawing period. Straw mulch reduced the range and variation of soil water evaporation by $0.55-1.04 \mathrm{~mm}$ and the influence of random factors on soil water evaporation. The results can provide references for rational and efficient utilization of soil water resources in spring. In the future, we will conduct further studies combining crop yields and water use efficiency.

\section{Acknowledgements}

This work was supported by National Natural Science Foundation of China (51279031, 51679039, 51479032), Excellent Youth Foundation of Heilongjiang Scientific Committee (JC201402), and Yangtze River Scholars in Universities of Heilongjiang Province. The authors express their gratitude to the editors and the anonymous reviewers for their valuable suggestions. The data related to this research are available to all interested researchers upon request.

\section{References}

Balwinder-Singh S, Eberbach P L, Humphreys E and Kukal S S 2011 The effect of rice straw mulch on evapotranspiration, transpiration and soil evaporation of irrigated wheat in Punjab, India; Agric. Water Manag. 98 18471855, https://doi.org/10.1016/j.agwat.2011.07.002.

Ben Neriah A, Assouline S, Shavit U and Weisbrod N 2014 Impact of ambient conditions on evaporation from porous media; Water Resour. Res. 50 6696-6712, https://doi. org/10.1002/2014WR015523.

Bond J J and Willis W O 1969 Soil water evaporation: Surface residue rate and placement effects; Sci. Soc. Am. J. 33 445-448, https://doi.org/10.2136/sssaj1969. 03615995003300030031x.
Bond J J and Willis W O 1970 Soil water evaporation: First stage drying as influenced by surface residue and evaporation potential; Soil Sci Soc. Am. J. 34 924-928, https:// doi.org/10.2136/sssaj1970.03615995003400060030x.

Cai T, Jia Z, Meng L, Guo F, Yang B, Huang Y and Ren X 2011 Effects of different rates of straw mulch on soil moisture and yield of spring maize in Weibei Highland area of China; Trans. Chin. Soc. Agric. Eng. 27 43-48.

Cai T, Zhang C, Huang Y, Huang H, Yang B, Zhao Z, Zhang $\mathrm{J}$ and Jia Z 2016 Effects of different straw mulch modes on soil water storage and water use efficiency of spring maize (Zea mays L.) in the Loess Plateau of China; Plant Soil Environ. 61 253-259, https://doi.org/10.17221/76/ 2015-PSE.

Cao J, Liu C, Zhang W and Guo Y 2012 Effect of integrating straw into agricultural soils on soil infiltration and evaporation; Water Sci. Technol. 65 2213-2218, https://doi. org/10.2166/wst.2012.140.

Chakraborty D, Nagarajan S, Aggarwal P, Gupta V, Tomar R, Garg R, Sahoo R, Sarkar A, Chopra U, Sundara Sarma K and Kalra N 2008 Effect of mulching on soil and plant water status, and the growth and yield of wheat in a semiarid environment (Triticum aestivum, L.) in a semi-arid environment; Agric Water Manag. 95 1323-1334.

Chen J, Zheng X, Qin Z, Liu P, Zang H and Sun M 2013 Effects of maize straw mulch on spatiotemporal variation of soil profile moisture and temperature during freeze-thaw period; Trans. Chin. Soc. Agric. Eng. 29 $102-110$.

Chen S Y, Zhang X Y, Pei D, Sun H Y and Chen S L 2007 Effects of straw mulching on soil temperature, evaporation and yield of winter wheat: Field experiments on the North China Plain; Ann. Appl. Biol. 150 261-268, https://doi. org/10.1111/j.1744-7348.2007.00144.x.

Davarzani H, Smits K, Tolene R M and Illangasekare T 2014 Study of the effect of wind speed on evaporation from soil through integrated modeling of the atmospheric boundary layer and shallow subsurface; Water Resour. Res. $50661-$ 680, https://doi.org/10.1002/2013WR013952.

Fan J, Gao Y, Wang O, Malhi S S and Li Y 2014 Mulching effects on water storage in soil and its depletion by alfalfa in the Loess Plateau of northwestern China; Agr. Water Manag. 138 10-16.

Figliola A and Serrano E 1997 Analysis of physiological time series using wavelet transforms; IEEE Eng. Med. Biol. Mag. 16 74-79.

Fu Q, Hou R, Liu D, Li T and Wang Z 2016 Spatial distribution of soil moisture content under condition of snowcover; Trans. Chin. Soc. Agric. Eng. 32 120-126.

Fu Q, Jiang R, Wang Z, Li T and Ma Z 2015a Soil moisture movement during freezing-thawing period under different snow covers; Trans. Chin. Soc. Agric. Eng. 46152 159.

Fu Q, Li T, Li T and Cui S 2015b Influence of straw mulching on soil moisture characteristics during seasonal freezethaw period; Trans. Chin. Soc. Agric. Eng. 46 141-146.

Fu Q, Ma Z, Li T and Jiang R 2014 Variability of soil temperature under different coverage conditions in alpine region of China; Trans. Chin. Soc. Agric. Eng. 45 152-159.

Fuchs M and Hadas A 2011 Mulch resistance to water vapor transport; Agric. Water Manag. 98 990-998, https://doi. org/10.1016/j.agwat.2011.01.008. 
Horton R, Bristow K L, Kluitenberg G J and Sauer T J 1996 Crop residue effects on surface radiation and energy balance-review; Theor. Appl. Climatol. 54 27-37, https:// doi.org/10.1007/BF00863556.

Huang Y, Chen L, Fu B, Huang Z and Gong J 2005 The wheat yields and water-use efficiency in the loess plateau: Straw mulch and irrigation effects; Agric. Water Manag. 72 209-222, https://doi.org/10.1016/j.agwat.2004.09.012.

Kang L and Zhang H 2016 A comprehensive study of agricultural drought resistance and background drought levels in five main grain-producing regions of China; Sustainability 8346.

Kar G and Kumar A 2007 Effects of irrigation and straw mulch on water use and tuber yield of potato in eastern India; Agric. Water Manag. 94 109-116, https://doi.org/ 10.1016/j.agwat.2007.08.004.

Lemon E R 1956 The potentialities for decreasing soil moisture evaporation loss; Soil Sci. Soc. Am. J. 20 120-125, https://doi.org/10.2136/sssaj1956. $03615995002000010031 x$.

Li Q, Chen Y, Mengyu L, Zhou X, Yu S and Dong B 2008 Effects of irrigation and straw mulching on microclimate characteristics and water use efficiency of winter wheat in north chinas; Plant Prod. Sci. 11 161-170, https://doi. org/10.1626/pps.11.161.

Li R, Hou X, Jia Z, Han Q, Ren X and Yang B 2013 Effects on soil temperature, moisture, and maize yield of cultivation with ridge and furrow mulching in the rainfed area of the Loess Plateau China; Agric. Water Manag. 116 101-109, https://doi.org/10.1016/j.agwat.2012.10.001.

Li R, Hou X, Jia Z, Han Q and Yang B 2012 Effects of rainfall harvesting and mulching technologies on soil water, temperature, and maize yield in loess plateau region of china; Soil Res. 50 105-113, https://doi.org/10.1071/SR11331.

Li S X, Wang Z H, Li S Q, Gao Y J and Tian X H 2013 Effect of plastic sheet mulch, wheat straw mulch, and maize growth on water loss by evaporation in dryland areas of China; Agric. Water Manag. 116 39-49, https:// doi.org/10.1016/j.agwat.2012.10.004.

Li X, Wang F, Hu L and Mu X 2011 Impact of wind-speed and straw-mulching on soil water evaporation; Agric. Res. Arid Area 29 186-190.

Liang J, Shi H, Li R, Ni D, Xu Z and Zheng Q 2015 Effect of mulching on salinized soil freezing and thawing characteristics and autumn irrigation quality; Trans. Chin. Soc. Agric. Eng. 46 98-105.

Niu L, Van Gelder P H A J M, Zhang C, Guan Y and Vrijling J K 2015 Statistical analysis of phytoplankton biomass in coastal waters: Case study of the Wadden Sea near Lauwersoog (The Netherlands) from 2000 to 2009; Ecol. Inform. 30 12-19, https://doi.org/10.1016/j.ecoinf.2015. 08.003

Ram H, Dadhwal V, Vashist K K and Kaur H 2013 Grain yield and water use efficiency of wheat in relation to irrigation levels and rice straw mulching in northwest India
[Triticum aestivum L. in relation to irrigation levels and rice straw mulching in northwest India]; Agric. Water Manag. 128 92-101.

Shaheen A, Ali S, Stewart B A, Naeem M A and Jilani G 2010 Mulching and synergistic use of organic and chemical fertilizers enhances the yield, nutrient uptake and water use efficiency of sorghum; Afr. J. Agric. Res. 162178 2183.

Siddique K H M, Tennant D, Perry M W and Belford R K 1990 Water use and water use efficiency of old and modern wheat cultivars in a Mediterranean-type environment; Aust. J. Agric. Res. 41 431-447, https://doi.org/10.1071/ AR9900431.

Sun B, Xie J, Wang N and Li C 2012 Effect of straw mulching on change of evaporation and water-salt in the saline soil; J. Soil Water Conserv. 26 246-250.

Sun B, Xie J, Wang N, Zhu J, Zhang J and Li C 2011 An experimental study of straw mulching effects in water and salt in saline soils; Soil Water Conserv. 31 48-51.

Vega J A, Fernández C, Fonturbel T, González-Prieto S and Jiménez E 2014 Testing the effects of straw mulching and herb seeding on soil erosion after fire in a gorse shrubland; Geoderma 223-225 79-87, https://doi.org/ 10.1016/j.geoderma.2014.01.014.

Vial L K, Lefroy R D B and Fukai S 2015 Application of mulch under reduced water input to increase yield and water productivity of sweet corn in a lowland rice system; Field Crop. Res. 171 120-129, https://doi.org/10.1016/j. fcr.2014.11.008.

Xing S, Zheng X and Chen J 2012 Experimental study on effect of corn residue management on soil water content during freezing-thawing period; Trans. Chin. Soc. Agric. Eng. 28 90-94.

Xue X, Jiang X, Huang Q and Wang Y 2002 The application of wavelet analysis in hydrological sequence trend analysis; J. Appl. Sci. 20 426-428.

Yan X, Ni Z, Chang L, Wang K and Wu D 2015 Soil warming elevates the abundance of Collembola in the Songnen Plain of china; Sustainability 7 1161-1171.

Zhang S, Yang X and Lovdahl L 2016 Soil management practice effect on water balance of a dryland soil during fallow period on the Loess Plateau of China; Soil Water Res. 11 64-73, https://doi.org/10.17221/255/2014-SWR.

Zhang X, Zhou Z and Liu J 2010 Melting of seasonal snow cover and its influence on soil temperature conditions of shallow layer; Trans. Chin. Soc. Agric. Eng. $2691-$ 95.

Zhao Y, Pang H, Wang J, Huo L and Li Y 2014 Effects of straw mulch and buried straw on soil moisture and salinity in relation to sunflower growth and yield; Field Crop. Res. 161 16-25, https://doi.org/10.1016/j.fcr.2014.02.006.

Zribi W, Aragüés R, Medina E and Faci J M 2015 Efficiency of inorganic and organic mulching materials for soil evaporation control; Soil Tillage Res. 148 40-45, https://doi. org/10.1016/j.still.2014.12.003. 